\title{
Argumento surgido num sonho
}

Andityas Soares de Moura Costa Matos

O experimento consiste em fazer conversar duas inteligências em um ambiente carente de quaisquer outros elementos. Trata-se de descobrir a prevalência do diálogo ou da evolução. A resposta é evidente quando se trata apenas de inteligências vivas. Portanto, o experimento só pode ser adequadamente realizado ao se utilizar, a cada ciclo, uma inteligência artificial e uma inteligência viva. Por comodidade, a inteligência viva do primeiro ciclo deve ser humana. $O$ procedimento é simples: a inteligência $A$ (humana) apresenta à inteligência $B$ (artificial) uma imagem (i1) que a representa, de modo que a IB, sem outros estímulos - importante lembrar que o ambiente virtual em que a IB existe (vive?) não está conectado à internet e nem a qualquer outra rede -, gere uma segunda imagem (i2) com base na primeira (i1). Esse é o primeiro ciclo. De acordo com os idealizadores do experimento (onírico), ele deve se estender por diversos outros ciclos para que i2 seja exibida a outra inteligência viva (IC) não necessariamente humana - menino, menina, arbusto, passarinho, mudo peixe do mar (Empédocles, Vitae philosophorum, VIII, 77) - que, por seu turno, gerará uma terceira imagem (i3). Esta será apresentada à mesma inteligência artificial do primeiro ciclo (IB). Ela então conceberá uma quarta imagem (i4), que será exposta a outra inteligência viva (ID) e assim sucessivamente. $O$ esquema ideal do experimento é o seguinte:

$$
I A(i 1)+I B=i 2 m I I I C+i 2=i 3 m I B+i 3=i 4 \quad I \prime I I D+i 4=i 5 \quad m I I B+i 5=i 6
$$

Ou seja:

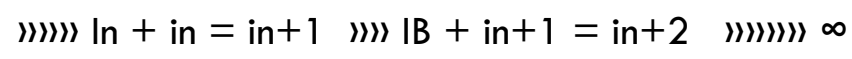

Até aqui, o experimento clássico. $O$ jogo começa quando, depois da geração da segunda imagem por meio da relação entre IA e IB, já não se apresenta tal imagem a outra inteligência viva IC (no limite, $I_{n}$ ) para que gere i3, mas se põe i2 diante de IB, de maneira que, assim enganada (pensando estar lidando com outra inteligência viva e não consigo mesma), IB dá à luz uma nova imagem (i4), que the será apresentada para que possa parir outra (i5) e assim indefinidamente (i6...in). $O$ experimento se transforma em jogo autorreferencial e inconsciente entre $I B$ e suas imagens representativas, com as quais, a partir de certo momento, ela entra em contato, já não sendo possível qualquer relação (abole-se a representação? Cf. Colli, La ragione errabonda, Milano, 1982). Eis o esquema:

$$
I A(i 1)+I B=i 2 m I B+i 2=i 3 m I B+i 3=i 4 m I B+i 4=i 5 m I B+i 5=i 6
$$

este é um artigo publicado acesso aberto (Open Access) sob a licença Creative Commons Attribution, que permite uso, distribuição e reprodução em qualquer meio, sem restrições desde que sem fins comerciais e que o trabalho original seja corretamente citado.

Ou seja:

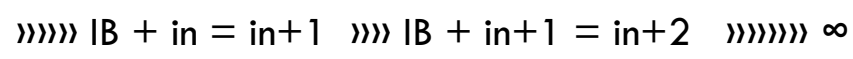

Estas são algumas das imagens nascidas do jogo: 


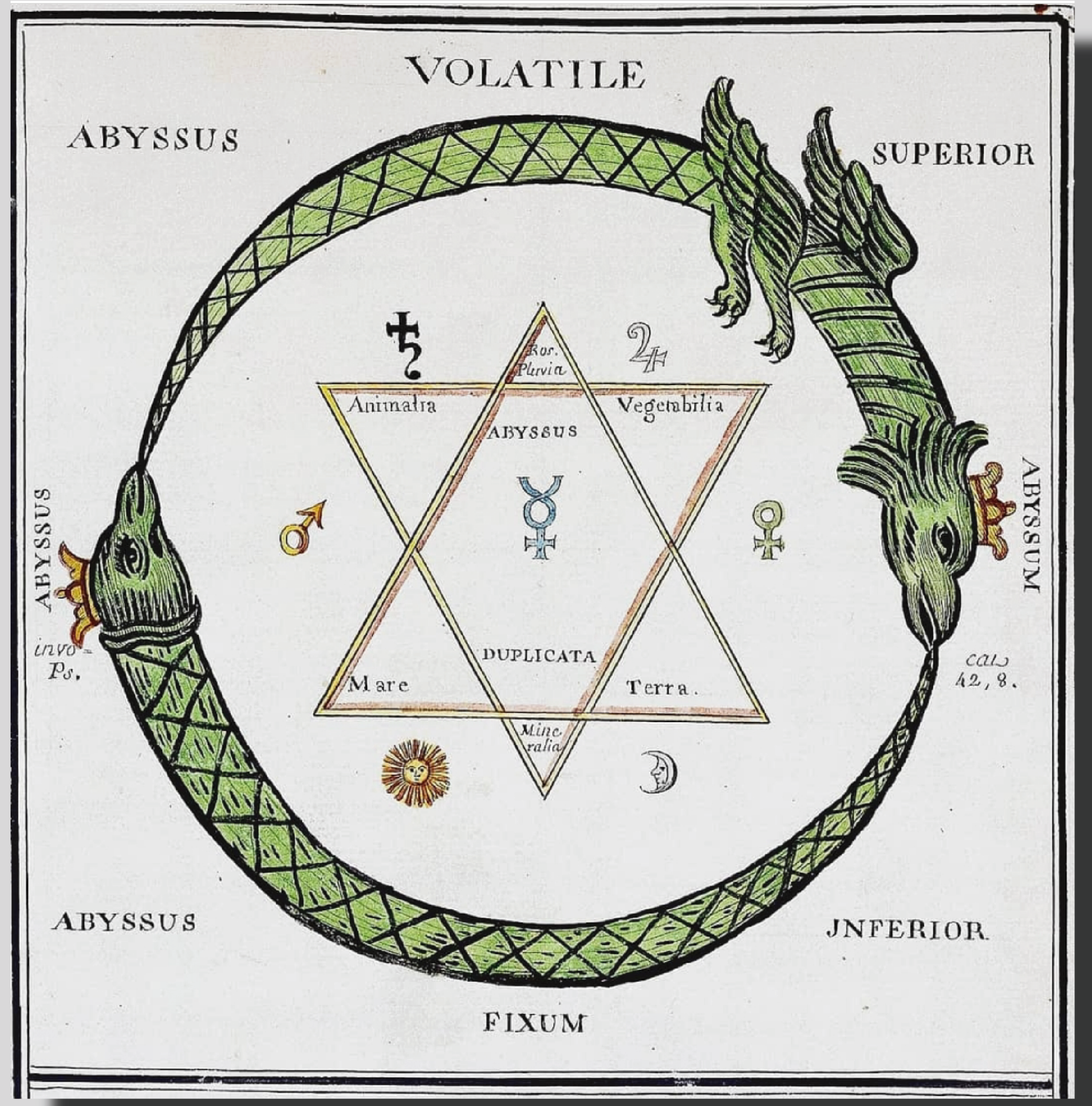




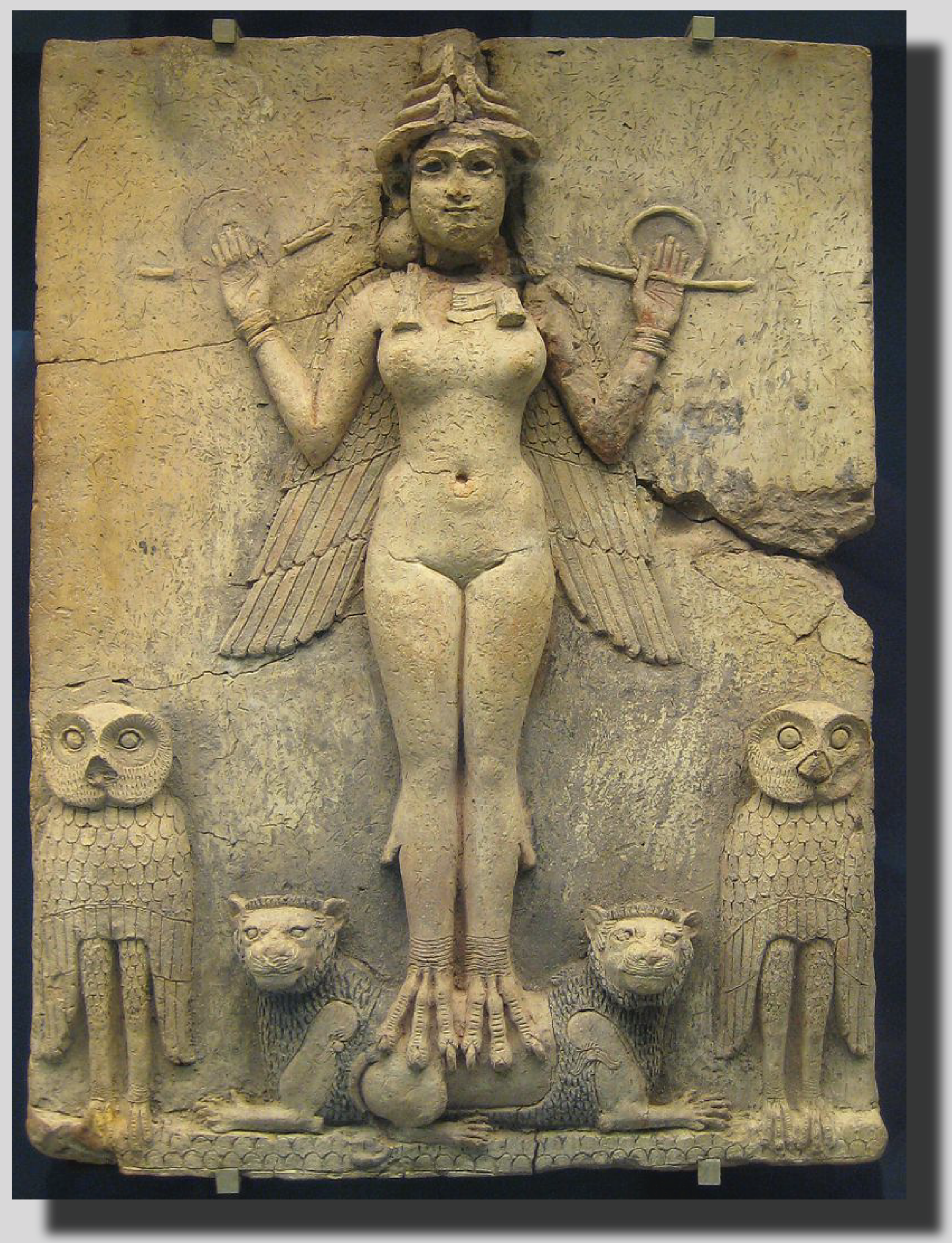




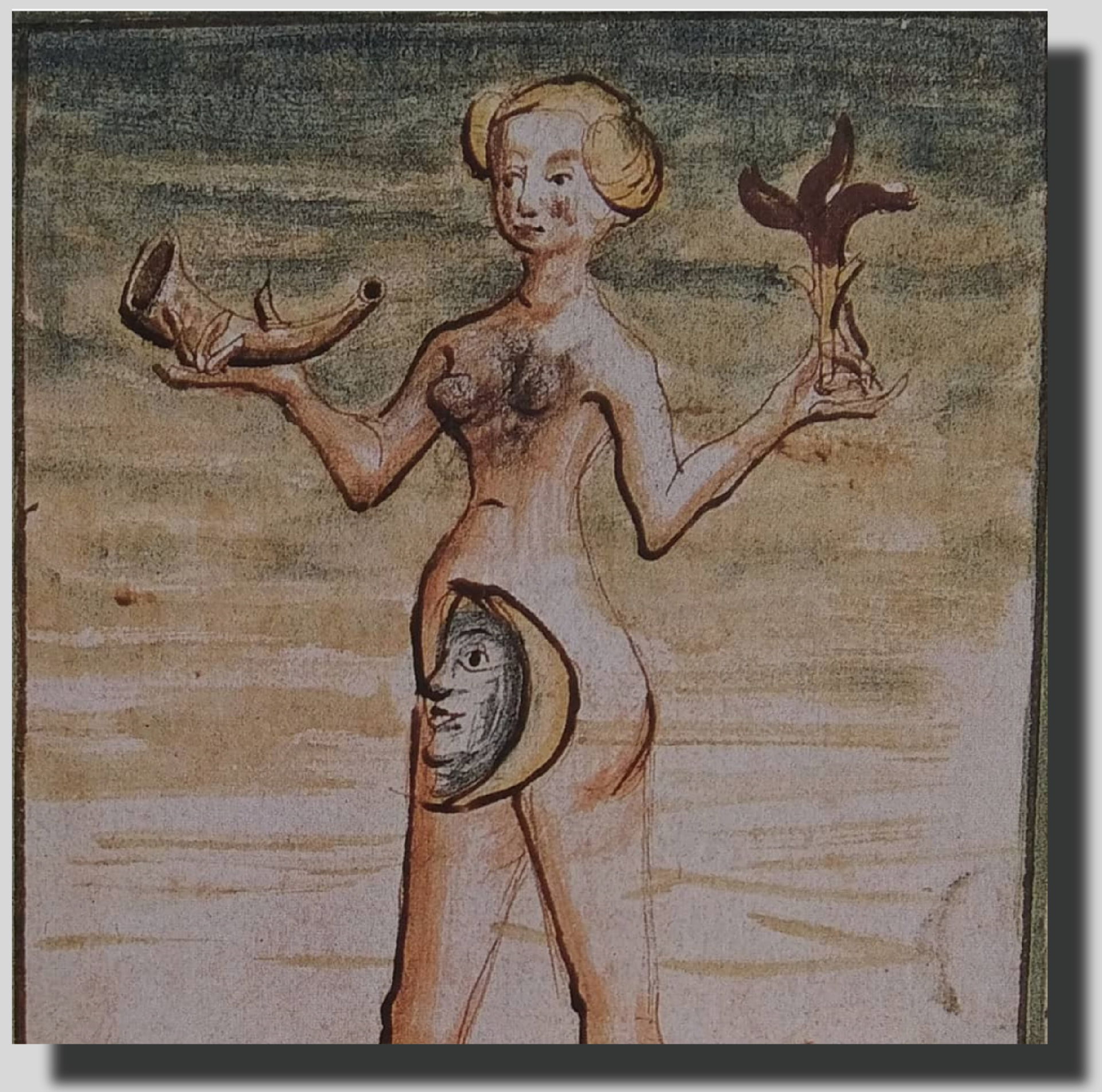




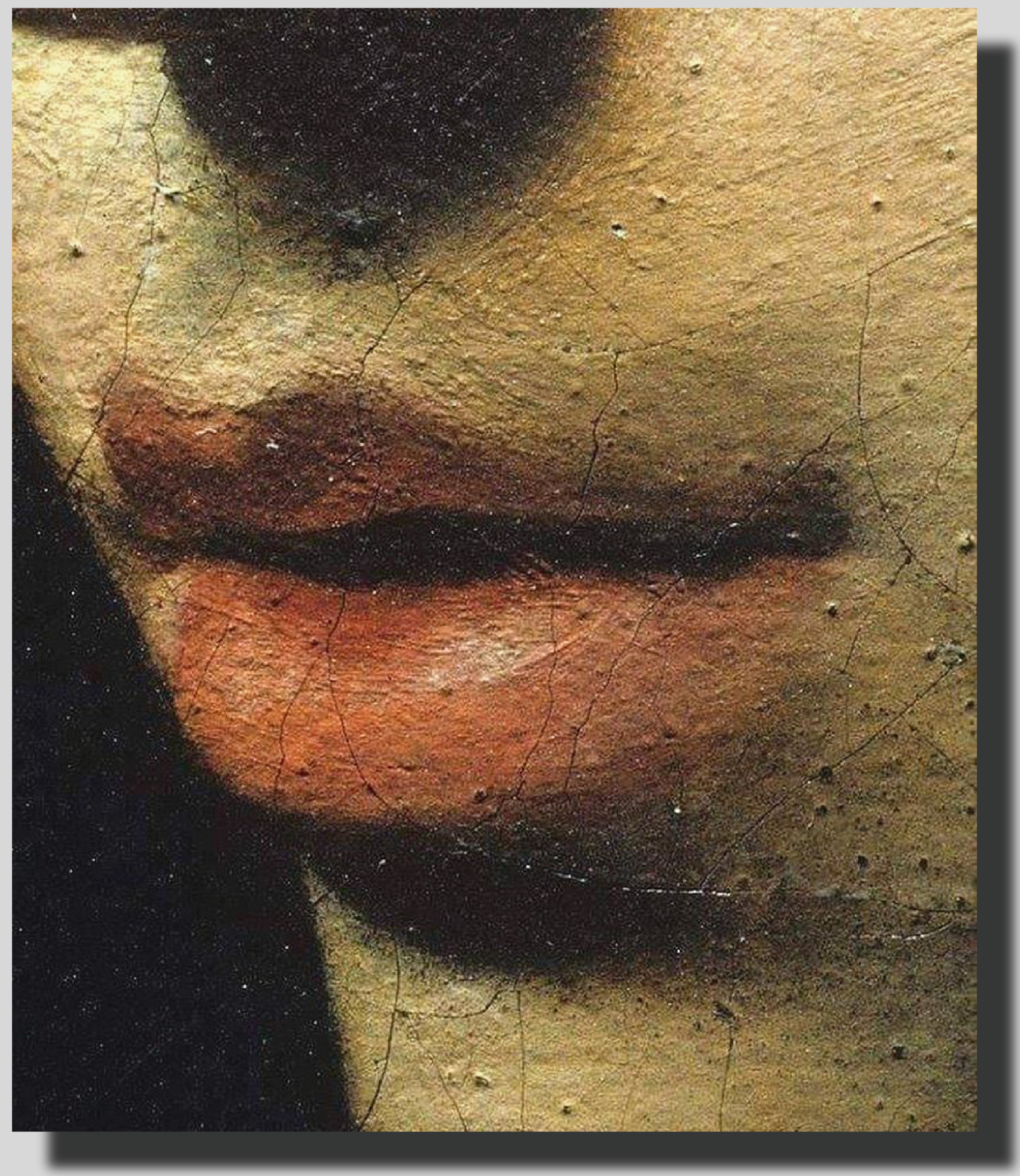




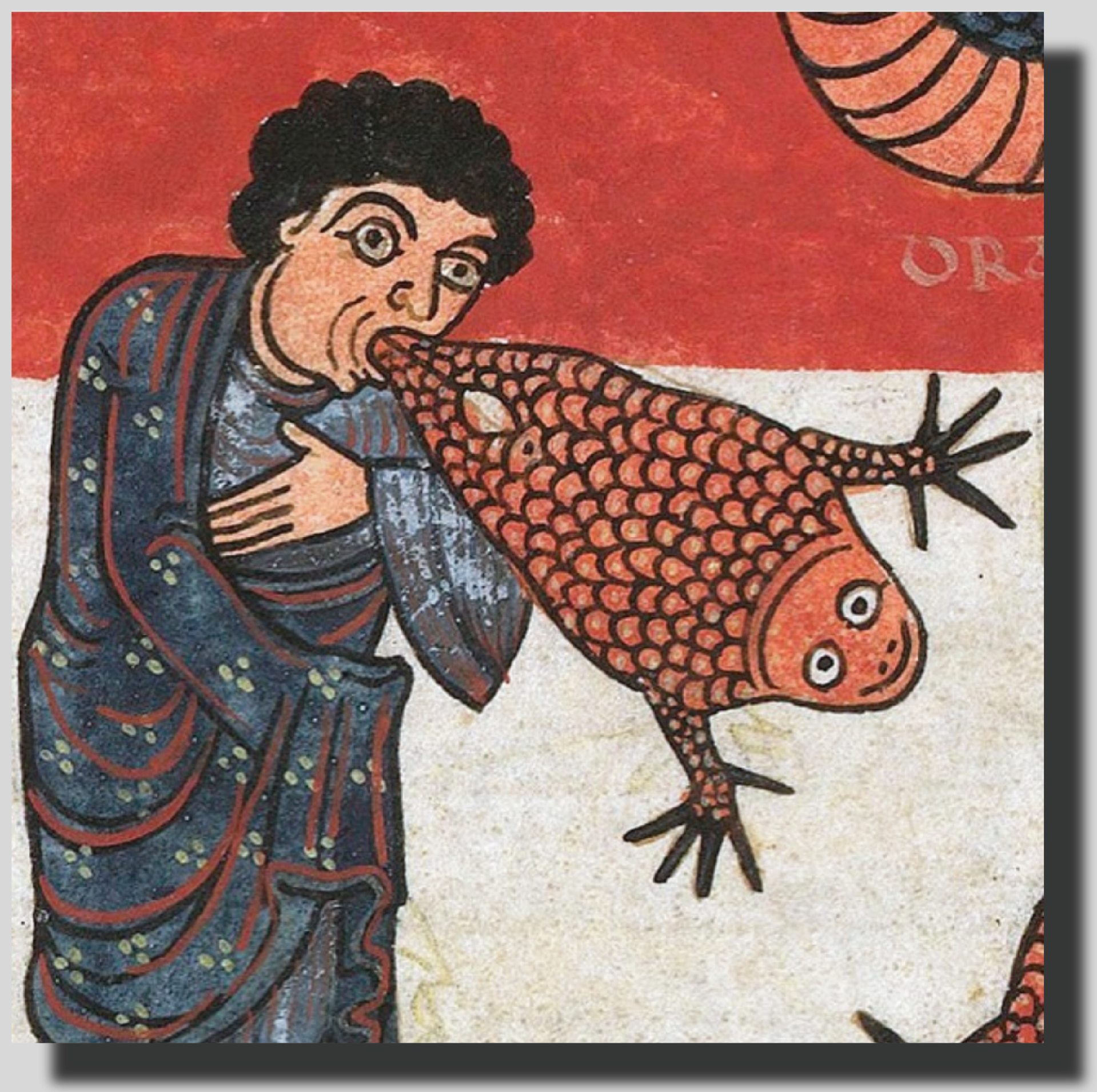




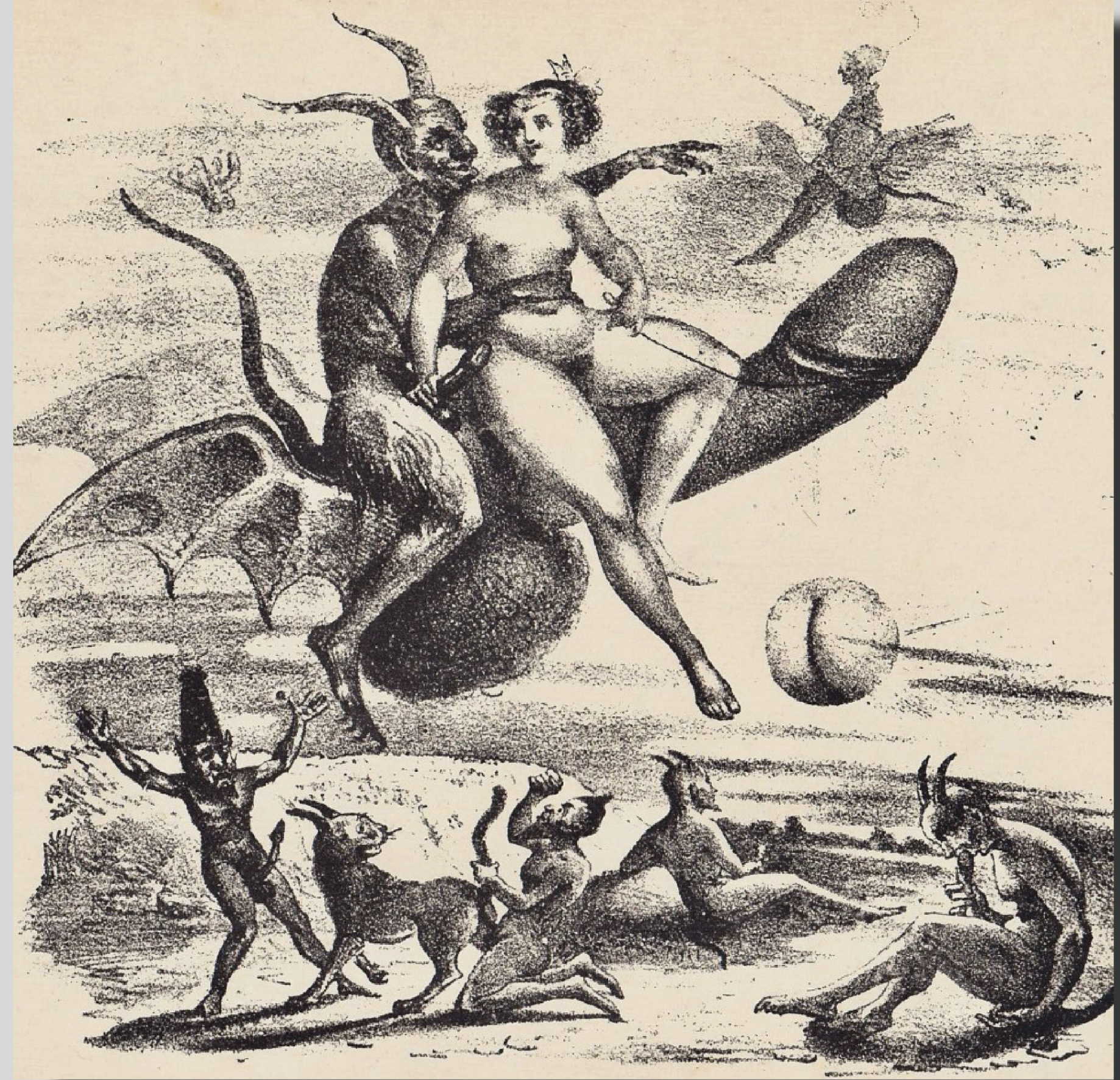




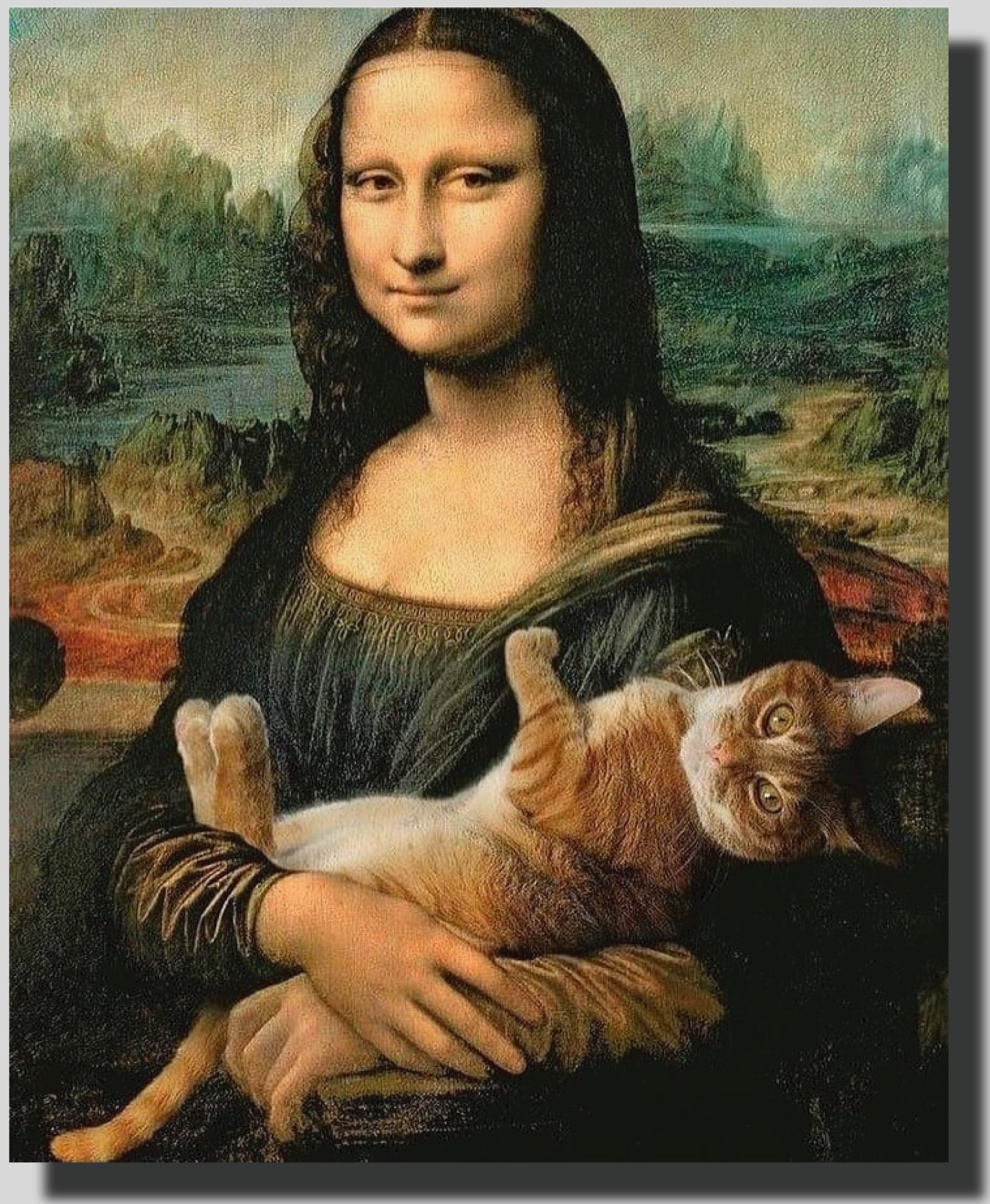




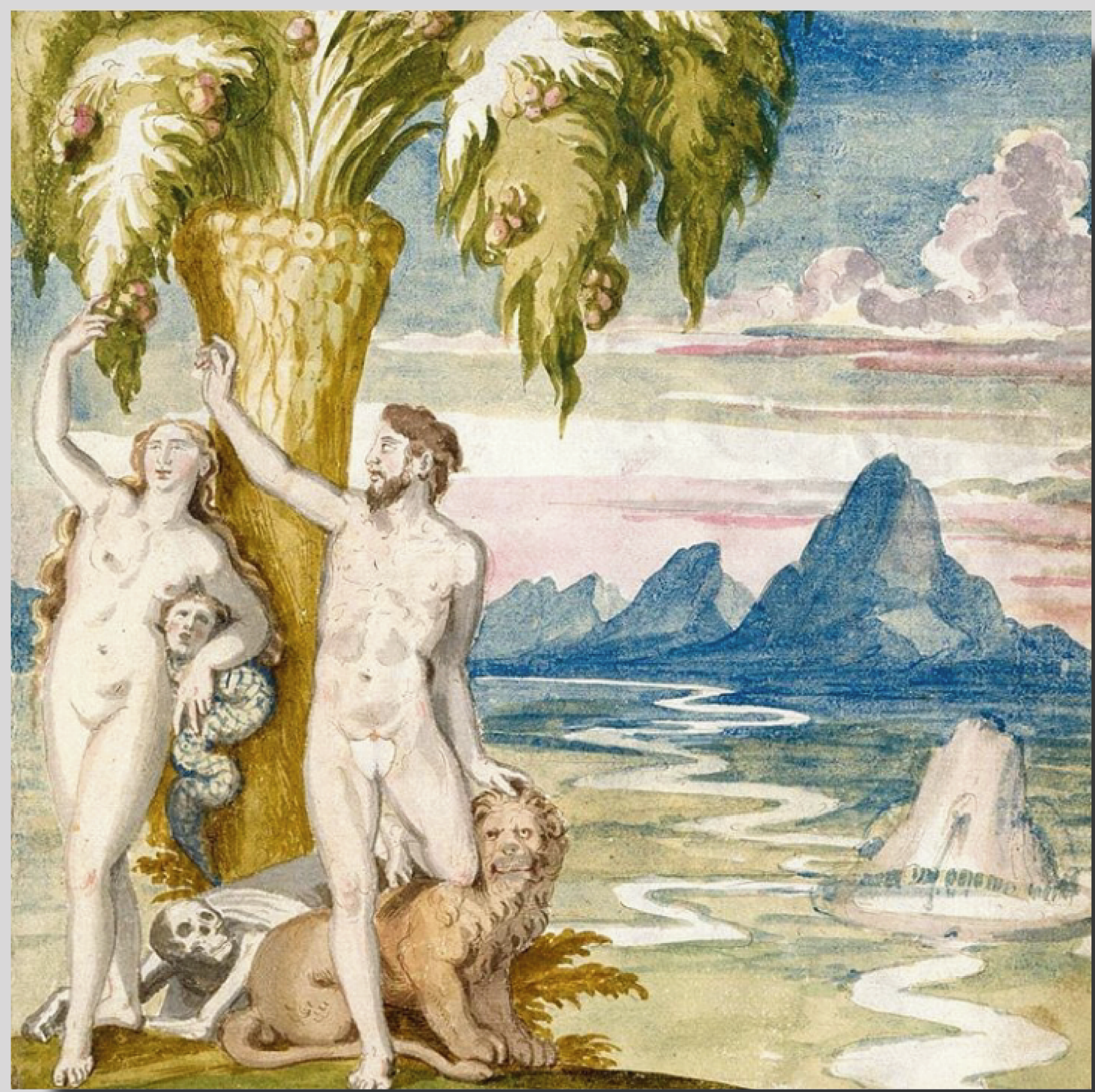




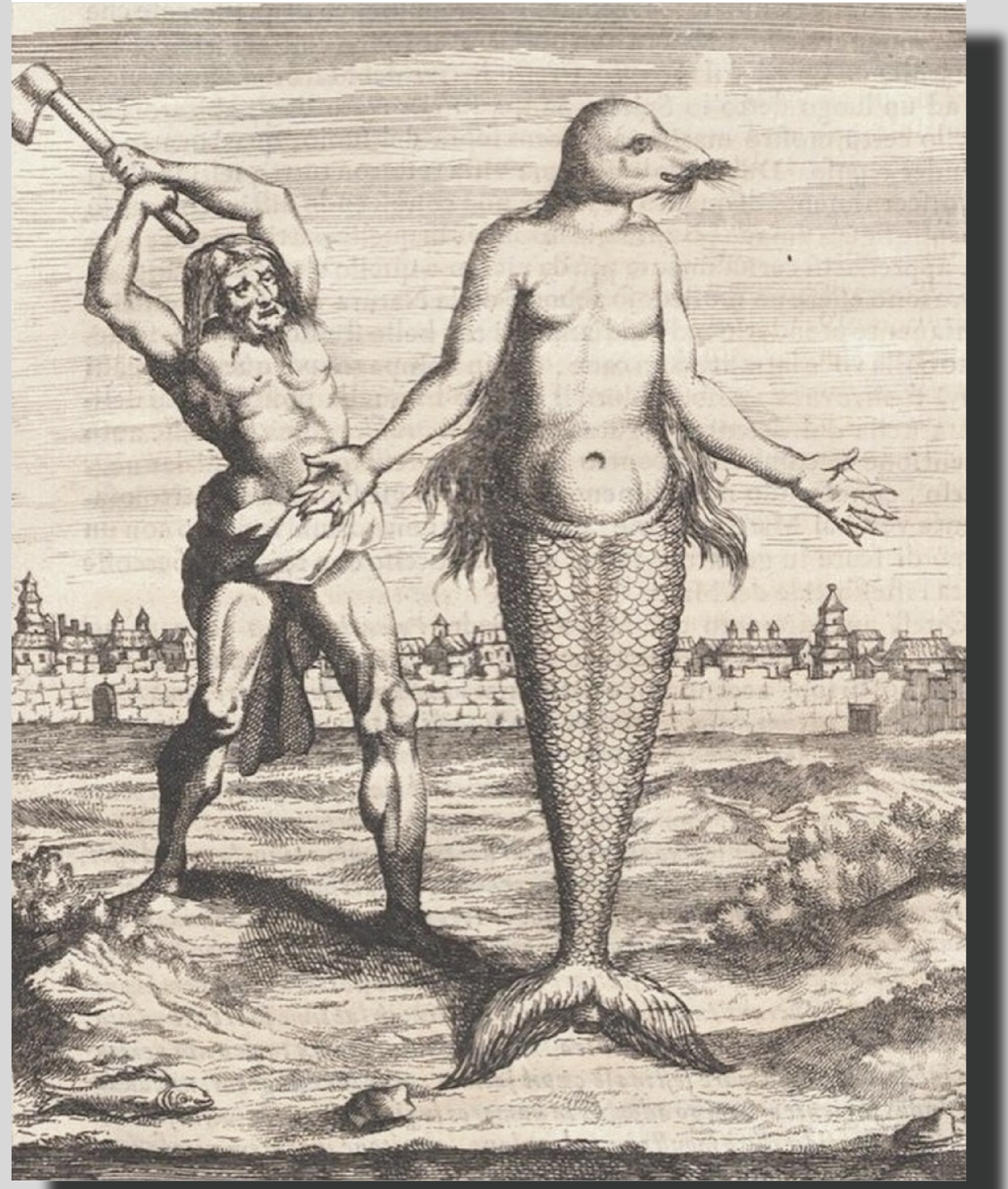




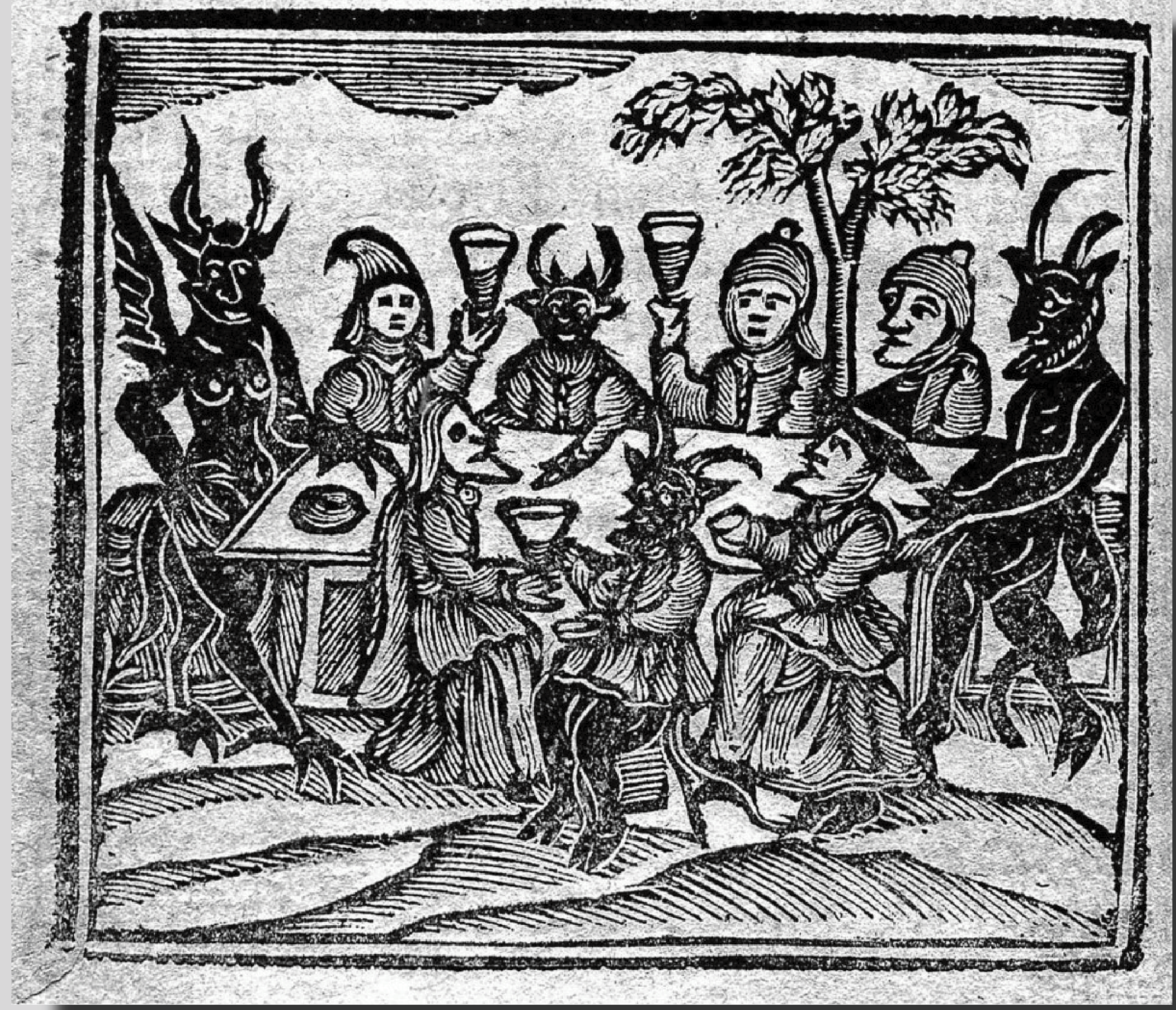




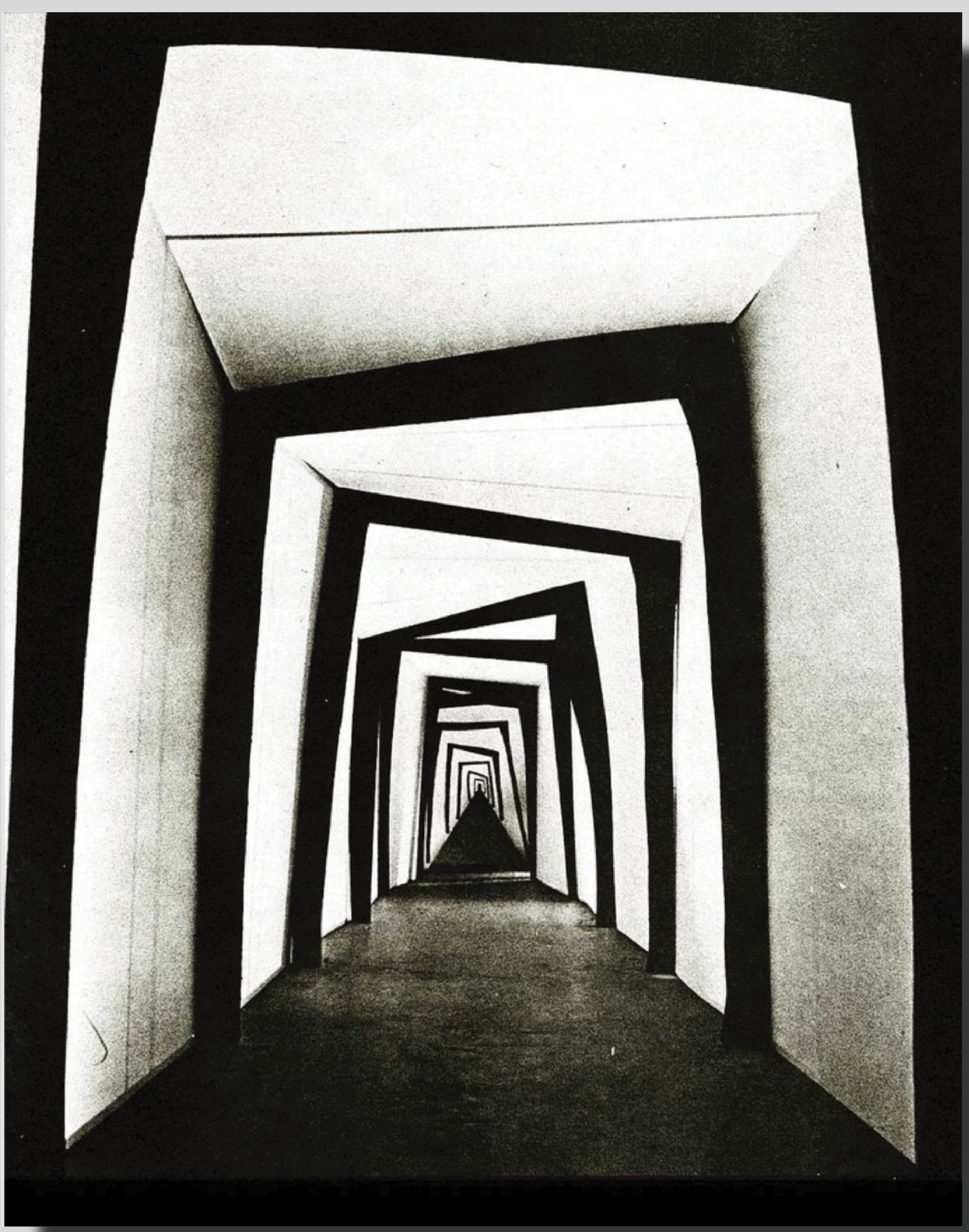




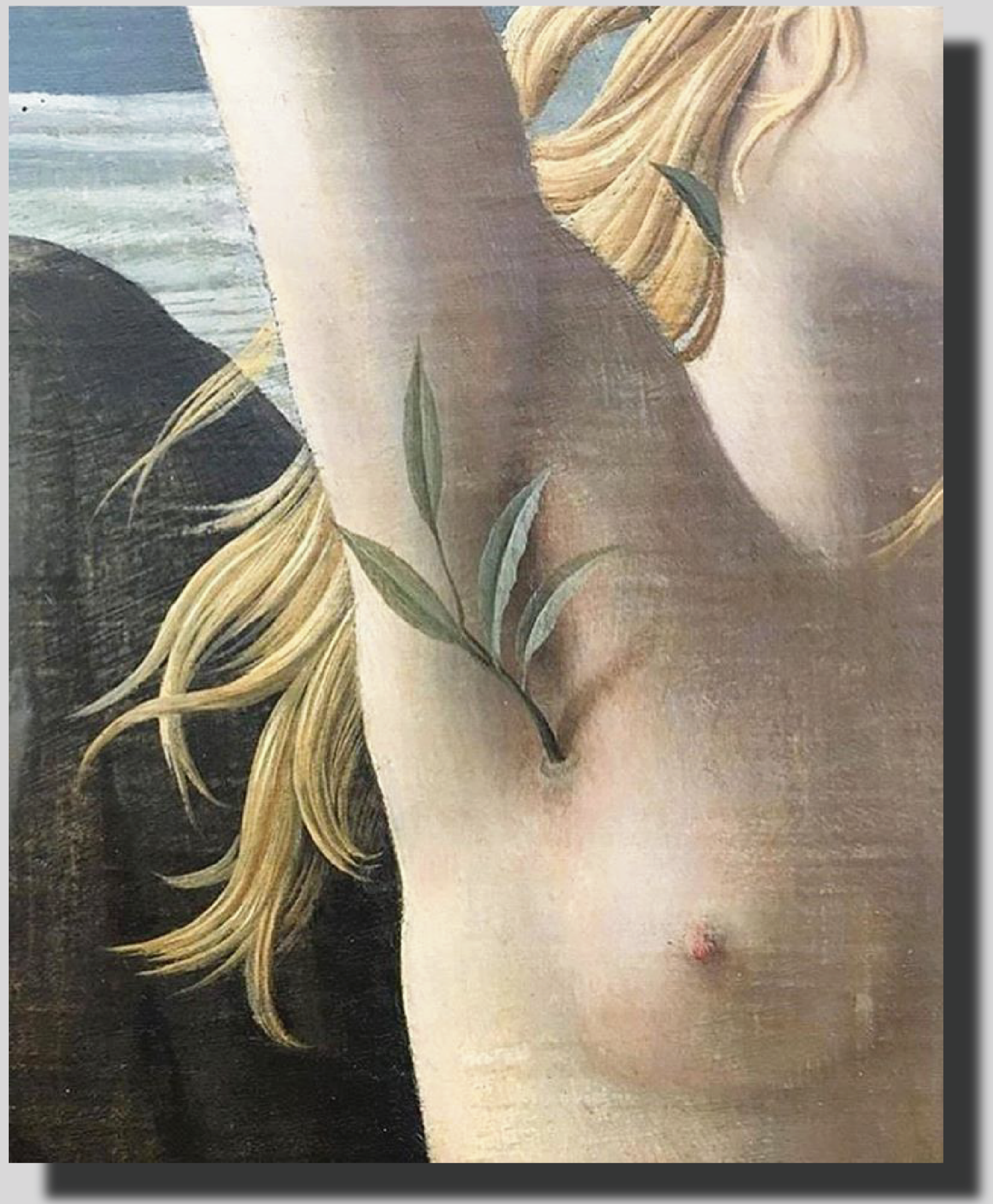

